\title{
Psychosis in a Case of Mycoplasma Pneumonia Encephalopathy
}

\author{
Alan Jay Cohen, MD \\ University of California at San Francisco
}

Follow this and additional works at: https://jdc.jefferson.edu/jeffjpsychiatry

Part of the Psychiatry Commons

Let us know how access to this document benefits you

\section{Recommended Citation}

Cohen, MD, Alan Jay (1986) "Psychosis in a Case of Mycoplasma Pneumonia Encephalopathy," Jefferson Journal of Psychiatry. Vol. 4 : Iss. 2 , Article 10.

DOI: https://doi.org/10.29046/JJP.004.2.012

Available at: https://jdc.jefferson.edu/jeffjpsychiatry/vol4/iss2/10

This Article is brought to you for free and open access by the Jefferson Digital Commons. The Jefferson Digital Commons is a service of Thomas Jefferson University's Center for Teaching and Learning (CTL). The Commons is a showcase for Jefferson books and journals, peer-reviewed scholarly publications, unique historical collections from the University archives, and teaching tools. The Jefferson Digital Commons allows researchers and interested readers anywhere in the world to learn about and keep up to date with Jefferson scholarship. This article has been accepted for inclusion in Jefferson Journal of Psychiatry by an authorized administrator of the Jefferson Digital Commons. For more information, please contact: JeffersonDigitalCommons@jefferson.edu. 


\title{
Psychosis in a Case of Mycoplasma Pneumonia Encephalopathy
}

\author{
Alan Jay Cohen, M.D.
}

Mycoplasma pneumonia, a well known cause of acute respiratory infection in man, has been reported to frequently include central nervous system manifestations as part of its clinical course $(1,2)$. The spectrum of neurologic syndromes associated with the disease is vast, ranging from direct invasion of brain and meninges by the organism to non-invasive parainfectious encephalopathy (3). This is a case report of an individual who presented to the emergency room in an acute psychotic state as the single manifestation of a parainfectious encephalopathy secondary to mycoplasma pneumonia infection of the lung.

\section{CASE REPORT}

Mr. A., a 34-year-old single Asian male without prior psychiatric history and in good health, one week prior to admission developed a febrile illness with temperature elevations to $105^{\circ} \mathrm{F}$. accompanied by nausea and vomiting. He was diagnosed as having an upper respiratory infection at a local medical clinic and given ampicillin on an outpatient basis. The patient returned home no longer complaining of physical symptoms. However, relatives reported the patient's behavior became aberrant. His usual restrained and conservative manner and scrupulous personal habits were supplanted by hostile, isolative, and slovenly behavior. His usually meticulous apartment was in complete disarray. He proposed marriage to a casual female acquaintance and made financially disastrous real estate investments. He refused help from his family members, confining himself to his apartment as his illness progressed. He stopped taking the ampicillin and started ingesting vitamin $\mathrm{C}$ tablets on a daily basis. The family called the police to help escort the patient to the hospital when he became combative with them.

On admission to the medical emergency room, the patient was severely agitated, requiring four-point restraints. He demonstrated marked affective lability from anger to euphoria and elation. His speech was bizarre in character, form, and content. "I am the King." He demonstrated pressured speech, loose associations, and flight of ideas. Perseveration, echolalia, and clanging were present at times. He appeared to be

The author wishes to thank Dr. Donna Ferriero, Department of Neurology, University of California at San Francisco; Dr. Ed Merrin, Department of Psychiatry, University of California at San Francisco; and Dr. Robert Hoffman, Department of Psychiatry, McAuley Neuropsychiatric Institute, San Francisco, California. Dr. Cohen wrote this paper while a fourth-year resident at the University of California at San Francisco. 
posturing despite the cloth restraints. He was responsive to painful stimuli in all four extremities but would not cooperate with tests of orientation and cognition.

Physical exam revealed a well developed male with stable vital signs and normal rectal temperature $\left(37^{\circ} \mathrm{C}\right), \mathrm{BP} 130 / 80$, Pulse 88 . His head and neck as well as cardiac and respiratory exams were normal. Abdominal and extremity examinations were also normal except for generalized paratonia in the muscles of the limbs and back. Neurological examination showed no gross deficits or focal signs, no meningismus, weakness, nystagmus, nor frontal release signs. Reflexes were symmetrical with toes downgoing.

Laboratory values in the E.R. showed normal values for CBC, electrolytes, glucose, calcium, phosphate, urinalysis, PT, PTT, EKG, and arterial blood gas. The patient did not cooperate for chest x-ray. In light of the clinical setting, altered mental status following a febrile illness, further studies seemed indicated on an emergency basis. CAT scan of the brain without contrast was attempted but unsuccessful due to movement artifact. The patient was sedated with $5 \mathrm{mg}$ haloperidol IM to obtain a lumbar puncture. Results showed clear CSF, 2 WBC, 6 RBC, 2\% PMN, glucose 74 (peripheral 80) and total protein 24-all indicative of little, if any, acute inflammatory process in the CNS. At this point the patient was admitted to the Medicine service for further evaluation and treatment. He received gastric lavage and charcoal for possible drug toxicity. Toxic screens of urine and blood were obtained and a KUB x-ray was performed without evidence of pill fragments. The patient remained less combative throughout the night and reevaluation by psychiatric and neurologic consultation services in the morning further clarified the clinical picture. Both services found evidence of cognitive deficits at that time suggesting an organic mental syndrome. The patient continued to show inappropriate hypersexuality on the ward and bizarre behavior during examinations (e.g., using stethoscope as a telephone). An EEG was obtained which showed a normal baseline but considered an inadequate study due to patient noncompliance.

The patient was then transferred to the Neurology service where further evaluation revealed a right middle lobe infiltrate on chest x-ray. Repeat lumbar puncture was obtained with little change in inflammatory response $6 \mathrm{WBC}, 85 \%$ lymph, glucose 73 and protein 20). Bacterial and fungal cultures, antiviral serologic titers and VDRL of the $\mathrm{CSF}$ were sent to the laboratory. Bedside cold agglutinins were drawn and were markedly positive. The patient was initiated on a course of erythromycin $500 \mathrm{mg}$ p.o. QID for presumed mycoplasma pneumonia infection of the lung. Haloperidol $5 \mathrm{mg}$ p.o./IM QD was given for agitation. The patient showed improvement in his behavioral disturbances over the next four days and was transferred to another facility for continuing care. His chest $\mathrm{x}$-ray showed significant improvement on a repeat study. Mycoplasma titers of blood were reported positive at $>1: 512$ at our facility and 1:16,384 at the continuing care hospital. CSF serologies were negative. All blood, CSF, and sputum cultures were negative, as were drug toxic screens. The patient was reported to have cleared completely from his acute encephalopathy at final discharge, two weeks after his admission. He returned home and was lost to followup.

\section{DISCUSSION}

This case illustrates several important aspects of evaluation and treatment of psychotic states secondary to organic brain syndromes. Establishing the 
diagnosis of organic brain syndrome can be difficult when behavioral disturbances preclude adequate cognitive testing and the "organic" etiology is obscure. Acutely psychotic patients with bipolar illness or schizophrenia may present with identical behavioral disturbances and nonspecific cognitive deficits on examination despite no known "organic" causes. In emergency room settings, therefore, complete medical and neurological evaluation may be inadequate due to patient noncompliance and the paucity of physical symptomatology at presentation. This certainly impacts upon treatment decisions, such as using rapid neuroleptization to calm the acutely psychotic and agitated patient. In the case presented, the establishment of the diagnosis of organic brain syndrome avoided the complications of high dose neuroleptic treatment which may have confused the clinical picture and possibly worsened the patient's medical condition. Low dose neuroleptic treatment for agitated delirium, well described in the literature (4), was the treatment of choice in this case.

Krauthammer and Klerman (5) and DSM-III (6) have established criteria for differentiating organic brain syndromes from secondary manias or schizophrenic disorders. However, to completely assess the mental status of the acute psychotic patient, time may be required to stabilize and observe the patient. Serial testing of cognitive skills may be necessary to adequately establish a tentative diagnosis. Immediate management of the acutely psychotic patient often demands treatment without the luxury of time. The choice of low dose neuroleptics in this case, coupled with continued reevaluation of mental status and extensive medical and neurological testing, yielded the correct diagnosis and institution of appropriate antibiotic therapy.

Another interesting aspect of this case is the singular manifestation of psychosis in this respiratory illness. By improved understanding of the neurotoxicity of the mycoplasma pneumonia parainfectious syndrome we may shed light on the mechanisms of brain dysfunction in psychotic states. In the literature, four mechanisms have been proposed to explain the encephalopathy (3). One theory suggests autoimmune mechanisms (7). Biberfeld has demonstrated a cross-reactivity of human antibody response to mycoplasma lipid antigen and human brain tissue. Antibody-antigen interaction may account for the cerebral dysfunction. Autoimmune mechanisms have been postulated as the cause for the hemolytic anemia syndrome also associated with the disease.

Another theory suggests a neurotoxin may be elaborated by the organism. Although none has been demonstrated in man, Mycoplasma neurolyticum does produce such a toxin in mice (8).

Thrombosis of the cerebral vessels (9) or direct invasion of specific regions of the CNS by the infectious agent are more remote causes for the encephalopathy.

This case has helped demonstrate the importance of careful and complete medical and neurological evaluation of acutely psychotic patients. Treatment issues have been discussed which may influence early decision-making, assessment, and subsequent therapeutic interventions. The interdisciplinary approach 
of medical, neurological, and psychiatric consultation helped to clarify the diagnosis of organic brain syndrome and supported the extensive search for the causative factors in the illness. The occurrence of psychosis in this particular disease, mycoplasma pneumonia, is very rare (less than $1 \%$ in one study) (3). However, we must be aware of these rare disorders in our stepwise evaluation procedures to ensure proper treatment. In addition, further research into the mechanisms of the neurotoxicity may help us understand cerebral dysfunction in psychosis.

\section{REFERENCES}

1. Yesnick L: Central nervous system complications of primary atypical pneumonia. Arch Intern Med 97:93, 1956.

2. Hodges GR, Fass RJ, Saslaw S: Central nervous system disease associated with mycoplasma pneumonia infection. Arch Intern Med 130:277, 1972

3. Ponka A: Central nervous system manifestations associated with serologically verified Mycoplasma pneumonia infection. Scand. J Infect Dis 12:175-184, 1980

4. Solow C: Psychotropic drugs in somatic disorders. Int J Psych in Med 6(1/2):267, 1975

5. Krauthammer C, Klerman GL: Secondary mania. Arch General Psych 35:1333-1339, 1978

6. DSM-III APA Diagnostic and Statistical Manual of Mental Disorders, Third Edition. Washington, DC 1980

7. Biberfeld G, Stenbeck J, Johnson T: Antibodies to brain and other tissues in cases of mycoplasma pneumonia infection. Clin Exp Immunol 8:139, 1971

8. Thomas L, Alen F, Bitensky MW, et al: Studies of PPLO infection II. J Exp Med 124:1067, 1966

9. Noran HH, Baker AB: The central nervous system in pneumonia, II. A pathological study. Am J Path 22:579, 1946 